QUARTERLY OF APPLIED MATHEMATICS

VOLUME LXVIII, NUMBER 1

MARCH 2010, PAGE 3

S 0033-569X(09)01191-1

Article electronically published on October 20, 2009

\title{
INTRODUCTION. DINNER SPEECH
}

\author{
BY \\ CATHLEEN MORAWETZ \\ Professor Emeritus, Courant Institute of Mathematical Sciences, New York University
}

It is a very special pleasure for me to be here to celebrate the seventieth birthday of Walter Strauss, my old friend and collaborator. Way back when Walter was a regular visitor to the analysis seminar at the Courant Institute, he was on his way to court Phyllis, and later to visit his ailing father to whom he was very devoted - first it was an excuse and later it was a relief to do mathematics.

I had written a paper on the decay of solutions of a certain semi-linear equation. Irving Segal, Walter's adviser, had directed me to that area and told Walter to look me up. Walter thought we just might be able to get a scattering theorem out of it all. Well, we did, and we had great fun doing it, getting that excitement only mathematicians can get as all little pieces of the proof fell into place. It is hard for me now to imagine that at the time the result was truly novel, stirred the community, had lots of follow-up and today, some thirty years later, is part of history. I take that back - it does get cited with fair regularity.

Thus began a friendship. I got to know Phyllis and heard about Walter's family as he heard about mine. Both families are now grown to include grandchildren (I even have a great grandson).

All in all, Walter and I published six papers together. One was also with Jim Ralston. We went on to diverse other things, I to return to transonic flow and Walter to forge ahead with a much more important problem, the nonlinear Schrödinger equation. That is the way of mathematicians.

The seventies were not such happy times in academic life or anywhere else, but working with Walter was for me a unique and special escape into the world of mathematics.

Let us now raise a glass in Walter's honor and wish him many more happy birthdays.

Received December 31, 2008.

(C)2009 Brown University 